\title{
Looking Back at the Past Year of Stem Cell Reviews and Reports
}

\author{
Mariusz Z. Ratajczak ${ }^{1}$
}

Published online: 24 October 2017

(C) Springer Science+Business Media, LLC 2017

The first year of $S C R R$ under new leadership closes with this December issue. We published almost 80 articles in 2017, which were carefully evaluated by me and five newly appointed section editors: Drs. Giovanni Camussi, Louis Pelus, Peter Quesenberry Edward Scott, and Henning Ulrich as well as 18 veteran and newly recruited editorial board members. This scholarly output was also critically dependent on our reviewers, and we are grateful to them for their hard work and dedication. SCRR covers a broad range of topics, including different aspects of stem cell biology and tissue/organ regeneration. We are open not only to clear scientific progress but also to new and challenging ideas as well as controversy. We follow the advice of Albert Einstein, who said "A blind belief in authority is worst enemy of truth."

In the past year we published several papers on progress in the various applications of induced pluripotent stem cells (iPSCs). Just to highlight a few outstanding papers, the Kang group published an excellent review of iPSC technology, the direct conversion of cells, and the reprogramming of enhancers in somatic cell nuclear transfer [1]. In a series of highly interesting papers, in April Issue of SCRR Connor discussed the application of iPSCs as a model for understanding Parkinson's disease, and Augustyniak compared currently available protocols to generate chondrocyte-like cell. Furthermore, in October issue Zatz described a potential strategy to employ these cells to treat amyotrophic lateral sclerosis (ALS). On the other hand, the Murakawa group discussed critically current problems with genomic instability in iPSCs that preclude their immediate application in

Mariusz Z. Ratajczak

mzrata01@louisville.edu

1 Stem Cell Institute, University of Louisville, 500 South Floyd Street, Louisville 40202, USA the clinic and proposed some solutions to this problem [2]. This issue is crucial to the therapeutic future of these cells.

It is well known that the only stem cells that have so far been successfully applied in regenerative medicine in patients and are safe are those isolated from postnatal tissues. To address this topic we published several excellent papers that focus on the application of mesenchymal stem cells (MSCs). Particularly worth mentioning is discussed in October issue of SCRR a new strategy to obtain decellularized extracellular matrices from MSC cultures, and in January issue a new application of MSCs to attenuate the adverse effects of immunosuppressive drugs against distinct $\mathrm{T}$ cell subpopulations. The application of MSCs isolated from Wharton's Jelly to support ex vivo expansion of hematopoietic stem cells is presented in February issue of SCRR, and in the current issue of our journal the application of these cells in the potential immunotherapy of lymphoma cells.

The biological effects of stem cells employed in tissue/ organ regeneration depend mainly on the secretion by these cells of several soluble factors and the release of extracellular microvesicles (ExMVs). The role of ExMVs in the regeneration of renal tubular cells was directly addressed by the Camussi group [3]. In another interesting paper published in the current issue of SCRR, Barrera-Ramirez addressed the role of ExMVs derived from bone marrow stromal cells from acute myeloid leukemia patients in the pathogenesis of this disorder. ExMVs represent an exciting new area of research, and we will be closely following further developments in this field.

Regenerative medicine is still looking for an efficient source of stem cells that could be employed in repairing damaged organs. Among several excellent papers published this year, we recommend in April issue the interesting review by the Borlongan group discussing current stem cell therapies in stroke, Napoli's paper on the role of stem cell 
therapy in the human cardiovascular system, and in January issue the paper by Ferraro on the application of dermal micrografts in the treatment of chronic ulcers.

Several interesting papers were also published that address the presence in adult tissues of pluripotent/multipotent stem cells, known as very small embryonic-like stem cells (VSELs). These small, rare cells play an important role in tissue and organ rejuvenation and slow the aging process are discussed in August issue of SCRR. The role of VSELs in gametogenesis and hematopoiesis was addressed in an excellent paper by Bhartiya [4], and in August issue of SCRR Smadja discussed a role of VSELs in angiogenesis. In the current issue Bhartiya critically addressed a presence of potential pluripotent stem cells in the adult tissues.

While focusing on normal stem cells we are also open to new ideas related to the concept of cancer stem cells, and we would like to direct the attention of our readers to two papers in particular. The first, from the Smith laboratory, draws an analogy between the regulation of signaling pathways in embryonic stem cells and in cancer stem cells [5]. In another paper in October issue Sellers et al. posed the challenging question of whether we can isolate true stem cells from established cancer cell lines. The authors propose that cancer cell lines do not have an established stem cell phenotype but rather a fluctuating phenotype. Finally, it is worth mentioning the excellent review on the application of cytometry in stem cell research published in August issue by one of the world's leading experts, Zbigniew Darzynkiewicz. In June, SCRR also published a special issue dedicated to organs-on-chips and 3D-bioprintng technologies, edited by Murat Elcin. This special issue included eight excellent articles discussing this emerging area in biotechnology and regenerative medicine.

In a short editorial it is not possible to summarize all of the papers that were published in SCRR over the past year. We encourage our readers to have a close look at the papers highlighted above as well as other outstanding papers. Going forward, Stem Cell Reviews and Reports will continue to report the latest discoveries and to entertain challenging and provocative ideas. We encourage you to submit your best work and help establish SCRR as a premier journal in this important field.

\section{References}

1. Kwon, D., Ji, M., Lee, S., Seo, K. W., \& Kang, K. S. (2017). Reprogramming enhancers in somatic cell nuclear transfer, iPSC technology, and direct conversion. Stem Cell Reviews and Reports, 13(1), 24-34.

2. Yoshihara, M., Hayashizaki, Y., \& Murakawa, Y. (2017). Genomic instability of iPSCs: challenges towards their clinical applications. Stem Cell Reviews and Reports, 13(1), 7-16.

3. Collino, F., Pomatto, M., Bruno, S., et al. (2017). Exosome and microvesicle-enriched fractions isolated from mesenchymal stem cells by gradient separation showed different molecular signatures and functions on renal tubular epithelial cells. Stem Cell Reviews and Reports, 13(2), 226-243.

4. Shaikh, A., Anand, S., Kapoor, S., Ganguly, R., \& Bhartiya, D. (2017). Mouse bone marrow VSELs exhibit differentiation into three embryonic germ lineages and germ \& hematopoietic cells in culture. Stem Cell Reviews and Reports, 13(2), 202-216.

5. Oren, O., \& Smith, B. D. (2017). Eliminating cancer stem cells by targeting embryonic signaling pathways. Stem Cell Reviews and Reports, 13(1), 17-23. 